\title{
Vitronectin Binds to Activated Human Platelets and Plays a Role in Platelet Aggregation
}

\author{
Erica Asch and Eckhard Podack* \\ Division of Rheumatic Diseases and Immunology, New York Medical College, Valhalla, New York 10595; and \\ *Department of Microbiology, University of Miami, Miami, Florida 33136
}

\begin{abstract}
Vitronectin (Vn) is a multifunctional 75-kD glycoprotein that is present in plasma and the extracellular matrix. Vn functions as a complement regulatory protein in plasma, and promotes the growth and attachment of cells in tissue culture. Recent cDNA cloning reveals that like other adhesive proteins, Vn contains the sequence Arg-Gly-Asp and binds to some members of the integrin class of adhesive membrane receptors. In liposomes, the platelet membrane glycoprotein complex IIb/IIIa binds Vn, as well as fibrinogen, von Willebrand factor, and fibronectin. We examined the binding of purified Vn to resting and stimulated human platelets. Vn bound to thrombin-stimulated platelets in a calcium-dependent, specific, and saturable manner with a $K_{d}$ of $320 \mathrm{nM}$ and 8,000 sites per platelet. Epinephrine or ADP stimulation led to specific binding with $K_{d} S$ of 93 and $116 \mathrm{nM}$, respectively. Binding was inhibited by the tetrapeptide Arg-Gly-Asp-Ser and by monoclonal and polyclonal antibodies to GPIIb/IIIa. Endogenous platelet Vn stores were identified in immunoblots of gel-filtered platelets and the surface expression of endogenous platelet Vn was thrombin inducible. Monoclonal as well as polyclonal antibodies to $\mathrm{Vn}$ inhibited platelet aggregation, suggesting that $\mathrm{Vn}$ plays a role in the formation of stable platelet aggregates. (J. Clin. Invest. 1990. 85:1372-1378.) integrin • GPIIb/IIIa • S-protein • receptor • Arg-Gly-Asp
\end{abstract}

\section{Introduction}

Vitronectin (Vn), ${ }^{1}$ also known as $\mathrm{S}$ protein (1) and serumspreading factor (2), is a multifunctional $75-\mathrm{kD}$ acidic glycoprotein present abundantly in plasma $(200-500 \mu \mathrm{g} / \mathrm{ml})$ and the extracellular matrix (2). Plasma Vn functions in the complement cascade to prevent innocent bystander cytolysis by binding fluid phase C5b-7 and forming soluble, noncytolytic complexes (3). Vn also forms complexes with thrombin and anti-thrombin III that, in vitro, retain thrombin catalytic activity (4-6). Vn promotes the growth in tissue culture of multiple cell lines by mediating cell attachment to the substratum (7), and a similar function in vivo is likely. $\mathrm{Vn}$ is present in the

Address correspondence to Dr. Erica Asch, Division of Rheumatic Diseases and Immunology, Vosburgh Pavilion, New York Medical College, Valhalla, NY 10595.

Received for publication 20 January 1988 and in revised form 17 October 1989.

1. Abbreviations used in this paper: RGD, arg-gly-asp; RGDS, arggly-asp-ser; RGES, arg-gly-glu-ser; Vn, vitronectin.

J. Clin. Invest.

(C) The American Society for Clinical Investigation, Inc.

$0021-9738 / 90 / 05 / 1372 / 07 \quad \$ 2.00$

Volume 85, May 1990, 1372-1378 extracellular matrix of glomerular and aortic basement membrane, in the elastic layers of normal vessels walls, and in normal human dermis $(2,8)$.

Recent cDNA cloning and amino acid sequencing reveal that $\mathrm{Vn}$ contains the tripeptide arg-gly-asp (RGD) and shares cell adhesion properties with other RGD-containing proteins (9) including fibrinogen, von Willebrand factor, and fibronectin. The latter three proteins have known roles in platelet aggregation and share a common receptor on the platelet surface (10). Fibrinogen binding to the platelet glycoprotein complex IIb/IIIa (GPIIb/IIIa) is critical for normal platelet aggregation (11-14). Von Willebrand factor binds to GPIb to mediate platelet adhesion, but is also capable of binding via an RGDcontaining domain to the GPIIb/IIIa complex $(15,16)$. Fibronectin also binds to GPIIb/IIIa on the activated platelet surface via an RGD domain (17-19). Antibodies to GPIIb/IIIa, fibrinogen, and fibronectin are capable of inhibiting platelet aggregation, suggesting that these platelet adhesive proteins may participate in a macromolecular complex that is critical for normal platelet aggregation (19-23).

GPIIb/IIIa on platelets is a promiscuous receptor for fibrinogen, von Willebrand factor, and fibronectin, and may also bind Vn (24). The purified GP IIb/IIIa complex, when incorporated into liposomes, binds fibrinogen, fibronectin, von Willebrand factor, and Vn in an RGD-dependent manner (24).

To investigate the role of $\mathrm{Vn}$ in platelet aggregation, we examined the binding of purified Vn to resting and to activated human platelets, and studied the effects of several anti$\mathrm{Vn}$ antibodies on platelet aggregation.

\section{Methods}

Purification of $V n$. Vn was purified by the method of Dahlback and Podack (25). 1 liter of fresh frozen plasma was absorbed with $\mathrm{BaCl}_{2}$ and then precipitated twice with polyethylene glycol (PEG) 3350 to a final concentration of $20 \%$. The precipitate was dissolved in $10 \mathrm{mM} \mathrm{Na}$ phosphate, 2 mM EDTA, 2 mM benzamidine $\mathrm{HCl}, 1 \mathrm{mM}$ glutathione, and $1 \mathrm{mM}$ PMSF, pH 7.0, and loaded onto a DEAE-Sephacel column. $\mathrm{Vn}$ was eluted from the exchange column with a 2-liter linear salt gradient to $0.3 \mathrm{M} \mathrm{NaCl}$. $\mathrm{Vn}$ was detected by fused rocket electrophoresis and the $\mathrm{Vn}$-containing fractions were concentrated by ammonium sulphate precipitation. The precipitate from a $70 \%$ ammonium sulphate cut was dissolved in $50 \mathrm{mM}$ Tris- $\mathrm{HCl}, 0.15 \mathrm{M} \mathrm{NaCl}, 2 \mathrm{mM}$ EDTA, $2 \mathrm{mM}$ benzamidine $\mathrm{HCl}$, and $1 \mathrm{mM}$ glutathione, $\mathrm{pH} 7.4$, dialyzed against the same buffer, and loaded onto a blue Sepharose column equilibrated in the same buffer. After washing the column to remove ceruloplasmin, the $\mathrm{Vn}$ was eluted with start buffer plus $1 \mathrm{M}$ $\mathrm{NaCl}$. Vn-containing fractions were concentrated by ultrafiltration (Amicon Corp., Danvers, MA) and further purified by gel filtration with S-200. Vn was assessed for purity by $7.5 \%$ SDS-PAGE reduced and unreduced, followed by silver staining of the gels (Bio-Rad Laboratories, Richmond, CA).

Antibodies. Polyclonal antisera to Vn was obtained by immunization of rabbits and goats with purified $\mathrm{Vn}$ followed by successive bleeds. Anti-Vn IgG was purified from antisera by $40 \%$ ammonium 
sulfate precipitation followed by dialysis and purification by DE-32 chromatography. The monospecificity of the polyclonal anti- $\mathrm{Vn}$ antisera and IgG was confirmed by Western blots of purified Vn, plasma, or serum using the antisera or $\mathrm{IgG}$ as a probe. Monoclonal anti-Vn antibodies 011-023, 011-58, 011-207, 011-251, and 011-292 were obtained from Cytotech (San Diego, CA). Polyclonal anti-GPIIb, antiGPIIIa, and anti-GPIV were a gift of Dr. Adam Asch (Cornell University Medical College, New York, NY). Monoclonal anti-GPIIb/IIIa (7E3 and 10E5) were a gift from Dr. Barry Coller (State University of New York, Stonybrook, NY). Monoclonal anti-Vn receptor (LM609) was a gift from Dr. David Cheresh (Scripps Clinic, La Jolla, CA) (26).

Crossed immunoelectrophoresis. Vn was labeled with carrier-free

${ }^{125}$ I (Amersham Corp., Arlington Heights, IL) by the iodogen method (27) to a sp act of $1-2 \times 10^{6} \mathrm{cpm} / \mu \mathrm{g}$ protein. The functional activity of ${ }^{125} \mathrm{I}-\mathrm{Vn}$ was assessed by measuring incorporation into SC $5 \mathrm{~b}-9$ complexes. ${ }^{125} \mathrm{I}-\mathrm{Vn}$ was added to serum before incubation with zymosan $\left(10 \mathrm{mg} / \mathrm{ml}\right.$; Sigma Chemical Co., St. Louis, MO) at $37^{\circ} \mathrm{C}$ for $1 \mathrm{~h}$. Zymosan was removed by centrifugation at $3,000 \mathrm{rpm}$ for $10 \mathrm{~min}$ and crossed immunoelectrophoresis was performed on the serum using polyclonal anti-C5 and anti-C 9 antisera as precipitating antibodies for SC5b-9 (3). The agarose gel was washed extensively with Tris-buffered saline ( $10 \mathrm{mM}$ Tris, $0.15 \mathrm{M} \mathrm{NaCl}, \mathrm{pH} 7.4$ ) and distilled water before drying and staining with $90 \%$ methanol, $7 \%$ acetic acid, $0.25 \%$ Coomassie blue (Bio-Rad Laboratories). The gels were subjected to autoradiography to demonstrate incorporation of functionally active ${ }^{125} \mathrm{I}-\mathrm{Vn}$ into SC5b-9 complexes.

Binding studies and time course. Gel-filtered human platelets were isolated from platelet-rich plasma collected in acid citrate dextrose containing $\mathrm{PGE}_{1}$ and aspirin as previously described (28). $100 \mu \mathrm{l}$ of platelet suspensions $\left(1 \times 10^{5} / \mu \mathrm{l}\right)$ were incubated with ${ }^{125} \mathrm{I}-\mathrm{Vn}$ in buffer containing $0.14 \mathrm{M} \mathrm{NaCl}, 2.7 \mathrm{mM} \mathrm{KCl}, 0.42 \mathrm{mM} \mathrm{NaH}_{2} \mathrm{PO}_{4}, 12 \mathrm{mM}$ $\mathrm{NaHCO}_{3}, 5.5 \mathrm{mM}$ glucose, $5 \mathrm{mM}$ Hepes, $2 \mathrm{mM} \mathrm{CaCl}_{2}, 1 \mathrm{mM} \mathrm{MgCl}$, and $1 \%$ albumin, $\mathrm{pH}$ 7.4. Platelets were activated with $10 \mu \mathrm{M}$ epinephrine, $6 \mu \mathrm{M}$ ADP, or $0.10 \mathrm{U} / \mathrm{ml}$ thrombin without stirring. In thrombin experiments, the thrombin inhibitor pro-phe-arg chloromethylketone was added at $4 \mathrm{~min}$ to a final concentration of $1 \mu \mathrm{M}$. After incubation for $1 \mathrm{~h}$, the platelets were spun through $400 \mu \mathrm{l}$ silicone oil and the bound radioactivity was quantitated (20). In some experiments, binding was performed in the presence of $100 \mu \mathrm{M}$ tetrapeptide arg-gly-aspser (RGDS) or arg-gly-glu-ser (RGES) (Peninsula Laboratories, Inc., Belmont, CA), $5 \mathrm{mM}$ EDTA, $8 \mu \mathrm{M}$ purified human fibrinogen (gift of Dr. M. Mosesson, Mt. Sinai Medical Center, Milwaukee, WI), 100 $\mu \mathrm{g} / \mathrm{ml}$ monospecific polyclonal anti-GPIIb/IIIa or anti-GPIV antibodies, or $10 \mu \mathrm{g} / \mathrm{ml}$ monoclonal anti-GPIIb/IIIa antibodies $10 \mathrm{E} 5$ or 7E3. For the time course, gel-filtered, epinephrine-stimulated human platelets were incubated with $200 \mu \mathrm{g} / \mathrm{ml}{ }^{125} \mathrm{I}-\mathrm{Vn}$ for various times, after which aliquots were removed and binding was measured as previously described. Specific binding was determined for resting and stimulated platelets in competitive inhibition studies: binding was performed in the presence of $1 \mu \mathrm{g}$ of ${ }^{125} \mathrm{I}-\mathrm{Vn}$ and various concentrations of unlabeled $\mathrm{Vn}$ with resting platelets and with platelets stimulated with $0.1 \mathrm{U} / \mathrm{ml}$ thrombin. Nonspecific binding was defined as noninhibitable $\mathrm{Vn}$ binding in cold competition studies. For infinite dilution studies, ${ }^{125} \mathrm{I}-\mathrm{Vn}$ at $200 \mu \mathrm{g} / \mathrm{ml}$ was incubated with thrombin-stimulated platelets for 30 $\mathrm{min}$. Some platelet suspensions were diluted 10 - or 50 -fold in the same buffer for $10 \mathrm{~min}$ before measuring binding.

Immunoblotting. $10^{8}$ gel-filtered resting platelets were pelleted by centrifugation at $2,000 \mathrm{~g}$ for $10 \mathrm{~min}$ and solubilized in buffer containing $1 \%$ SDS. Platelet extract, whole human plasma, and purified Vn were electrophoresed unreduced in a $7.5 \%$ SDS-polyacrylamide gel and transferred to nitrocellulose for immunoblotting (29). The nitrocellulose was probed with polyclonal anti- $\mathrm{Vn}$ antibody followed by horseradish peroxidase-conjugated goat anti-rabbit IgG and developed with the substrate chloronaphthol. Similar studies were also performed using monoclonal anti- $\mathrm{Vn}$ antibodies as probes and the appropriate second antibodies. In other experiments, anti- $\mathrm{Vn}$ antibody was preabsorbed with $\mathrm{Vn}$ immobilized on nitrocellulose before use of the antibody as a probe for similar immunoblots.
Measurement of the surface expression of endogenous platelet $V n$. The activation-dependent surface expression of platelet $\mathrm{Vn}$ was examined using ${ }^{125} \mathrm{I}$-monoclonal anti-Vn antibody $011-251$ or a control monoclonal antibody. Antibody was labeled with ${ }^{125} \mathrm{I}$ by the iodogen method to a sp act of $10^{6} \mathrm{cpm} / \mu \mathrm{g} .100 \mu \mathrm{l}$ of gel-filtered platelets (1 $\left.\times 10^{5} / \mu \mathrm{l}\right)$ in the presence of ${ }^{125} \mathrm{I}-011-251$ or an irrelevent ${ }^{125}$ I-labeled monoclonal antibody were stimulated with $10 \mu \mathrm{M}$ epinephrine or with $1 \mathrm{U} / \mathrm{ml}$ thrombin for $4 \mathrm{~min}$ without stirring. After incubation for 30 min the platelets were spun through silicone oil and the bound radioactivity in the platelet pellets was counted.

Platelet aggregation. Platelet aggregometry was performed using a Payton aggregometer (Payton Associates Ltd., Ontario, Canada) as previously described (20). Platelet-rich plasma or gel-filtered platelets $\left(1 \times 10^{6}\right)$ were aggregated by thrombin $(0.50,0.25$, or $0.10 \mathrm{U} / \mathrm{ml})$, epinephrine $(10,5$, or $2 \mu \mathrm{M})$, ADP $(6 \mu \mathrm{M})$, or collagen $(150 \mu \mathrm{g} / \mathrm{ml})$ in the presence of control or monospecific polyclonal anti- $\mathrm{Vn}$ antibodies $(100 \mu \mathrm{g} / \mathrm{ml})$ or monoclonal anti-Vn or control antibodies $(10 \mu \mathrm{g} / \mathrm{ml})$. Platelet secretion was monitored by measurement of ATP release from dense granules using a Lumi aggregometer (Chrono-Log Corp., Havertown, PA) as previously described (30).

\section{Results}

Binding of ${ }^{125} \mathrm{I}-\mathrm{V}$ n to human platelets. The binding of functionally active ${ }^{125} \mathrm{I}-\mathrm{Vn}$ to resting and stimulated gel-filtered human platelets was examined over a range of $\mathrm{Vn}$ concentrations in competitive binding studies with specific binding defined as that which is inhibitable by cold excess $\mathrm{Vn}$. The specific binding of $\mathrm{Vn}$ to platelets stimulated with $0.1 \mathrm{U} / \mathrm{ml}$ human thrombin was saturable. The data were analyzed by the computer LIGAND program and revealed a $B_{\max }$ of 8,000 sites per platelet and a $K_{\mathrm{d}}$ of $320 \mathrm{nM}$ (Fig. 1). Nonspecific binding was $0.002 \%$ of total input. Binding to resting platelets (data not shown) was not saturable and represented a maximum of $35 \%$ of total binding to stimulated platelets. The binding to resting platelets was similar to the measured nonspecific binding of $\mathrm{Vn}$ to activated platelets. In addition, ${ }^{125} \mathrm{I}-\mathrm{Vn}$ binding to resting platelets was not inhibited by a 100 -fold excess of cold $\mathrm{Vn}$, verifying that binding to resting platelets was nonspecific. LIGAND analysis revealed that binding to resting platelets was of very low affinity $\left(K_{\mathrm{d}}\right.$ of $\left.10 \mu \mathrm{M}\right)$ and equaled the nonspecific binding measured in stimulated platelets. Vn binding to epinephrine-stimulated platelets was similar with a $K_{\mathrm{d}}$ of $93 \mathrm{nM}$ and 23,828 $\pm 1,683$ sites/platelet. ADP-stimulated platelets bound $13,173 \pm 233$ molecules $V n$ /platelet with a $K_{d}$ of 116 nM. Subsequent binding data are expressed as specific binding. A time course revealed that maximal binding occurred at $20 \mathrm{~min}$ (Fig. 2). Binding was reversible by $87 \%$ in infinite dilution studies (Fig. 2). Binding to stimulated platelets was inhibited by $10 \mathrm{mM}$ EDTA, $8 \mu \mathrm{M}$ purified fibrinogen, $100 \mu \mathrm{M}$ synthetic RGDS, and by polyclonal as well as monoclonal antibodies to the glycoprotein IIb/IIIa complex (Figs. 3 and 4). Binding was not inhibited by $100 \mu \mathrm{M}$ RGES or by an irrelevant antibody (anti-GPIV). In contrast, binding to resting platelets was not calcium dependent and was not inhibited by RGDS or by antibodies to GPIIb/IIIa (data not shown). Platelet-bound ${ }^{125} \mathrm{I}-\mathrm{Vn}$ comigrated with purified $\mathrm{Vn}$ as a single band at $75 K_{d}$ in an autoradiograph of a $7.5 \%$ unreduced SDS-polyacrylamide gel (data not shown). There was no evidence of disulfide-linked dimers of platelet-bound $\mathrm{Vn}$.

Immunoblotting of endogenous platelet $\mathrm{Vn}$. The presence of endogenous platelet $\mathrm{Vn}$ was investigated in immunoblots of gel-filtered resting human platelets. $10^{8}$ gel-filtered platelets 


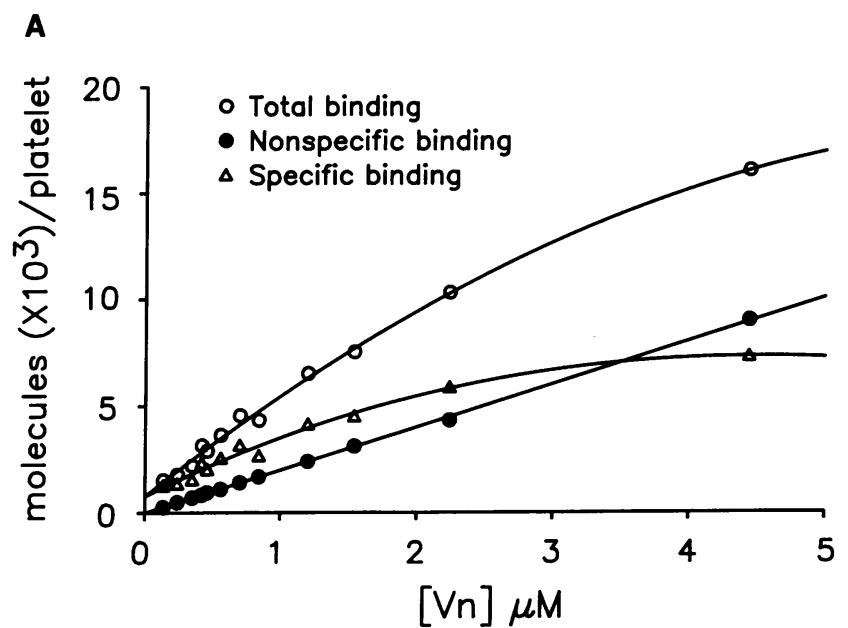

B

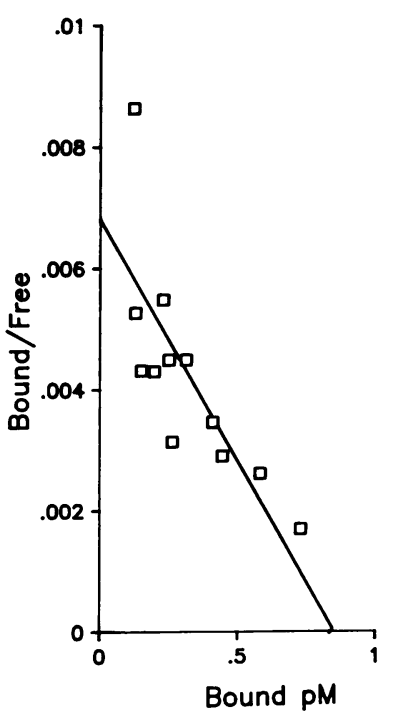

Figure 1. ${ }^{125} \mathrm{I}-\mathrm{Vn}$ binding to platelets. Vn was radiolabeled using the iodogen method and its functional activity was confirmed in crossed immunoelectrophoresis demonstrating incorporation of ${ }^{125} \mathrm{I}-\mathrm{Vn}$ into SC5b-9 complexes. Gel-filtered aspirinated human platelets were incubated with buffer or human thrombin $(0.1 \mathrm{U} / \mathrm{ml})$ in the presence of ${ }^{125} \mathrm{I}-\mathrm{Vn}$ and varying amounts of cold $\mathrm{Vn}$ for 60 min at room temperature. Bound $\mathrm{Vn}$ was separated from unbound by centrifugation through silicone oil and the bound radioactivity in the platelet pellet was quantitated. $A$ depicts Vn binding to thrombin-stimulated platelets. Open circles, total binding; closed circles, nonspecific binding defined as noninhibitable by excess cold $\mathrm{Vn}$; triangles, specific binding (total binding-nonspecific binding).

Points represent the mean of duplicates. Binding was saturable with 8,000 sites per platelet. $B$ is a Scatchard plot of the data. Individual replicates are plotted. A $K_{\mathrm{d}}$ of $320 \mathrm{nM}$ was derived from ligand analysis of the data.

were solubilized, subjected to $7.5 \%$ SDS-PAGE under nonreducing conditions, and electroblotted to nitrocellulose paper. Blots were probed with monospecific polyclonal anti-Vn IgG (Fig. 5) or with the monoclonal anti-Vn antibody 011-251. A single major band with an apparent $M_{\mathrm{r}}$ of $75 \mathrm{kD}$ was identified in lane 4 containing platelet lysate, as well as in control lanes containing purified Vn (lane 3), or whole plasma (lane 2). Polyclonal anti-Vn IgG preabsorbed with immobilized Vn failed to react with platelet extract, further confirming the specificity of the antisera. In addition, identical results were obtained using monoclonal anti-Vn antibody 011-251.

Surface expression of endogenous platelet $\mathrm{Vn}$. The activation-dependent surface expression of endogenous platelet $\mathrm{Vn}$ as measured by ${ }^{125} \mathrm{I}$-anti-Vn monoclonal 011-251 binding was examined after epinephrine or thrombin stimulation of gel-filtered aspirinated, $\mathrm{PGE}_{1}$-treated platelets. Fig. 6 depicts the

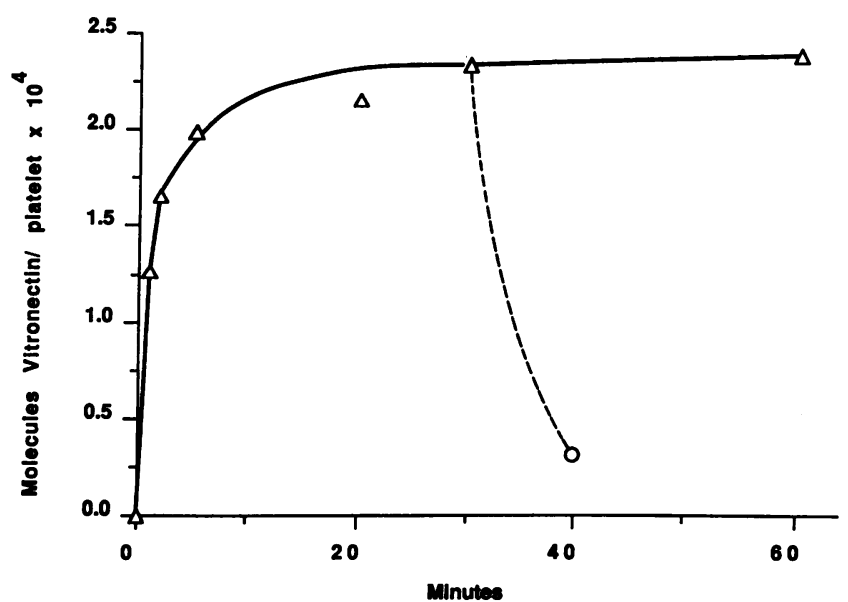

Figure 2. Time course and infinite dilution. Gel-filtered, epinephrine-stimulated $(10 \mu \mathrm{M})$ human platelets were incubated with ${ }^{125} \mathrm{I}-\mathrm{Vn}$ $(200 \mu \mathrm{g} / \mathrm{ml})$ at room temperature for various times after which aliquots were removed and bound $\mathrm{Vn}$ was quantitated. Maximal binding occurred at $20 \mathrm{~min}$. For infinite dilution experiments, aliquots were removed after $30 \mathrm{~min}$, diluted 10 - or 50 -fold with buffer, and incubated $10 \mathrm{~min}$ before measuring bound $\mathrm{Vn} .87 \%$ of bound $\mathrm{Vn}$ was removed by 50 -fold dilution (circle). Points represent the mean of duplicates.

binding of labeled anti-Vn monoclonal and control monoclonal to resting and epinephrine- and thrombin-stimulated platelets. Although $10 \mu \mathrm{M}$ epinephrine induced the binding of exogenous $\mathrm{Vn}$, it did not induce the surface expression of endogenous Vn. Gel-filtered aspirinated human platelets stimulated with $10 \mu \mathrm{M}$ epinephrine did not release granule contents

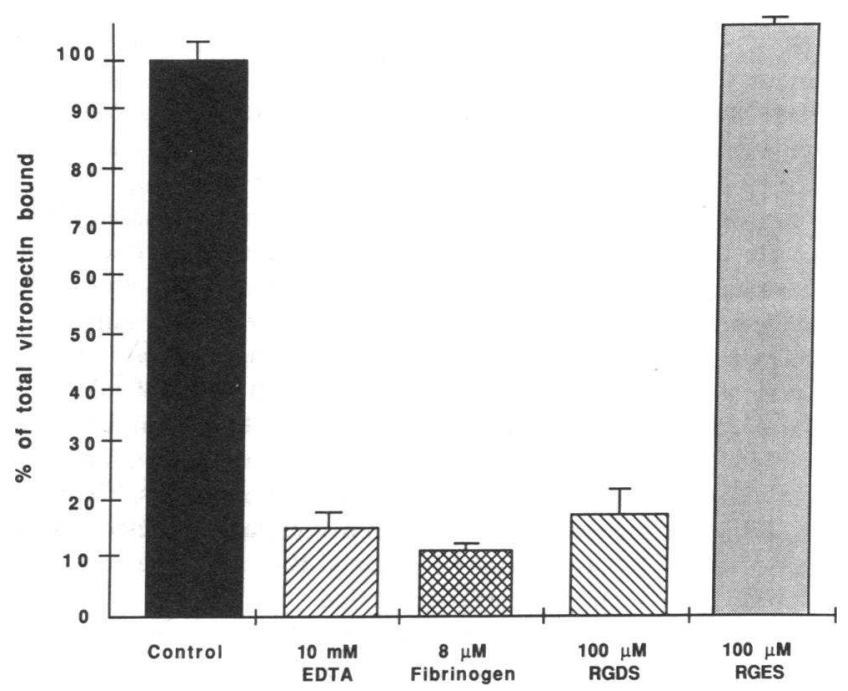

Figure 3. Inhibition of $\mathrm{Vn}$ binding by EDTA, RGDS, and fibrinogen. Gel-filtered human platelets were incubated with buffer, $10 \mathrm{mM}$ EDTA, $100 \mu \mathrm{M}$ RGDS, $100 \mu \mathrm{M}$ RGES, or $8 \mu \mathrm{M}$ fibrinogen before the addition of $100 \mu \mathrm{g} / \mathrm{ml}{ }^{125} \mathrm{I}-\mathrm{Vn}(1.5 \mu \mathrm{M})$ and thrombin $(0.10$ $\mathrm{U} / \mathrm{ml}$ ). Each bar represents the mean of duplicates in representative experiments portrayed as percentage of total specific binding. EDTA, RGDS, and fibrinogen inhibited the specific binding of ${ }^{125} \mathrm{I}-\mathrm{Vn}$ to stimulated platelets. Control peptide RGES did not inhibit binding. 


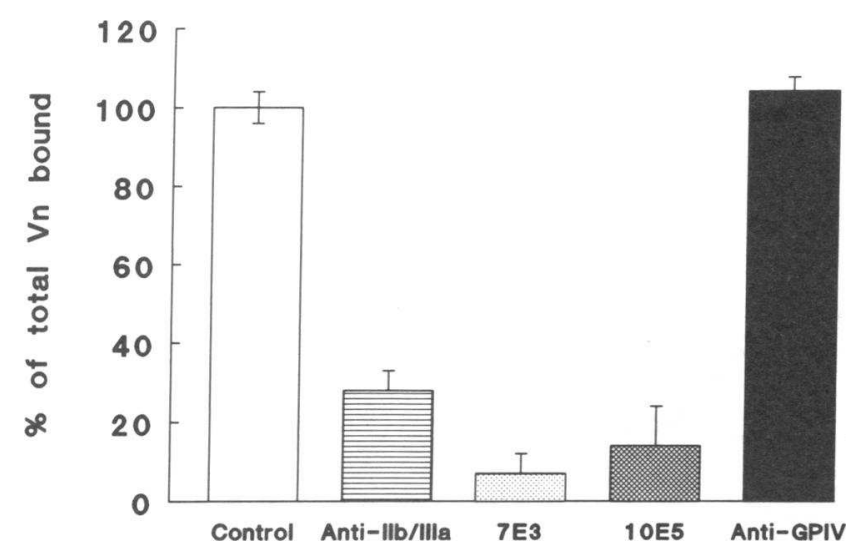

Figure 4. Inhibition of Vn binding by anti-GPIIb/IIIa antibodies. Gel-filtered human platelets were incubated with buffer, polyclonal anti-GPIIb/IIIa, or control (anti-GPIV) antibodies $(100 \mu \mathrm{g} / \mathrm{ml})$ or monoclonal anti-GPIIb/IIIa antibodies $10 \mathrm{E} 5$ or $7 \mathrm{E} 3(10 \mu \mathrm{g} / \mathrm{ml})$ before the addition of ${ }^{125} \mathrm{I}-\mathrm{Vn}(1.5 \mu \mathrm{M})$ and thrombin $(0.1 \mathrm{U} / \mathrm{ml})$. Both polyclonal and monoclonal anti-GPIIb/IIIa antibodies but not control antibody inhibited specific $\mathrm{Vn}$ binding.

as measured by ATP release using a Lumi aggregometer (data not shown). Thrombin stimulation leads to the surface expression of endogenous platelet Vn but $10 \mu \mathrm{M}$ epinephrine does not. These data suggest that the release and surface expression of platelet $\mathrm{Vn}$ is dependent on the release of platelet granule contents and not only on the induction of competent Vn binding sites. Surface expression was not inhibited by the anti-Vn receptor monoclonal antibody LM609 directed against the endothelial cell Vn receptor (CD51) (26), but was inhibited by anti-GPIIb/IIIa antibodies (data not shown) as was the case with fluid phase binding of $\mathrm{Vn}$.

Platelet aggregometry. The role of $\mathrm{Vn}$ in platelet aggregation was examined in aggregometry experiments. Experiments were performed using platelet-rich plasma stimulated with epi-

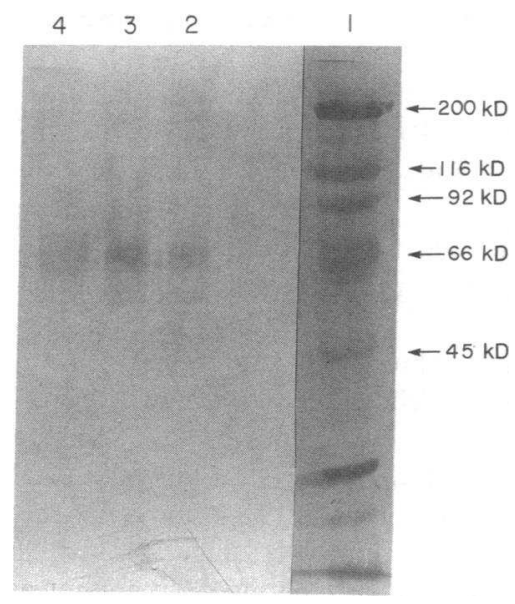

Figure 5. Immunoblotting of resting gel-filtered human platelets. Gel-filtered resting human platelets were solubilized in $1 \%$ SDS and run unreduced in a $7.5 \%$ gel, transferred to nitrocellulose, and probed with a monospecific polyclonal antiVn antibody. Lane 1 contained molecular weight markers. Lane 2 contained normal human plasma and demonstrated the monospecificity of this

antisera. Lane 3 contained purified Vn. Lane 4 contained solubilized gel-filtered platelets. A single band with an apparent $M_{\mathrm{r}}$ of $75 \mathrm{kD}$ corresponded to endogenous platelet $\mathrm{Vn}$. Antibody preabsorbed with $\mathrm{Vn}$ immobilized on nitrocellulose was used as a probe and failed to react with platelet extract in a similar experiment, further confirming the identity of the band in lane 4 as $\mathrm{Vn}$.

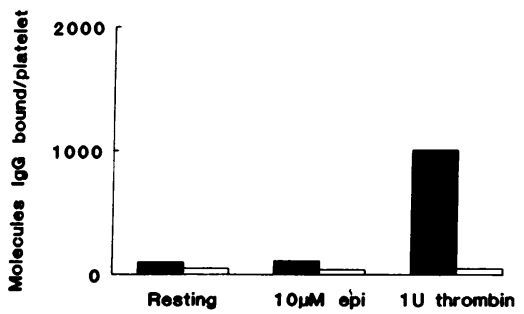

Figure 6. Surface expression of endogenous platelet Vn. Gel-filtered, aspirinated, $\mathrm{PGE}_{1^{-}}$ treated human platelets were incubated with buffer, epinephrine (10 $\mu \mathrm{M})$, or thrombin (1.0 $\mathrm{U} / \mathrm{ml})$ in the presence of $3 \mu \mathrm{g} / \mathrm{ml}{ }^{125} \mathrm{I}$-labeled monoclonal anti-Vn antibody or an irrelevant labeled monoclonal. After incubation the platelets were spun through silicone oil and the bound radioactivity in the platelet pellet was counted. There was no difference in the surface expression of $\mathrm{Vn}$ on resting or epinephrinestimulated platelets (active GPIIb/IIa sites but no platelet granule secretion), whereas thrombin-activated platelets bound 10 -fold more $\mathrm{Vn}$. This dose of thrombin has been shown to induce secretion of platelet granule contents. $10 \mu \mathrm{M}$ epinephrine did not induce platelet release of granule contents as measured by ATP release by Lumi aggregometry (data not shown). In control studies, no difference in the binding of an irrelevant ${ }^{125} \mathrm{I}$-monoclonal antibody was noted. Solid bars, monoclonal anti- $\mathrm{Vn}$; open bars, control monoclonal antibody.

nephrine, ADP, thrombin, or collagen in the presence of polyclonal or monoclonal control or anti-Vn antibodies. Buffer, epinephrine (10, 5, or $2 \mu \mathrm{M}), \operatorname{ADP}(5 \mu \mathrm{M})$, thrombin $(0.5,0.2$, and $0.1 \mathrm{U} / \mathrm{ml})$, or collagen $(150 \mu \mathrm{g} / \mathrm{ml})$ were used to induce platelet aggregation in platelet-rich plasma in the presence of normal rabbit IgG, polyclonal monospecific anti-Vn IgG (100 $\mu \mathrm{g} / \mathrm{ml})$, or monoclonal anti-Vn $(10 \mu \mathrm{g} / \mathrm{ml})$. Polyclonal anti-Vn IgG but not control IgG inhibited epinephrine-induced platelet aggregation in platelet-rich plasma (Fig. 7). In addition, anti-Vn IgG but not control IgG inhibited ADP- and thrombin-, but not collagen-induced platelet aggregation in plateletrich plasma (data not shown). Similar results were obtained with the monoclonal anti-Vn antibodies 011-292 and 011-58 $(10 \mu \mathrm{g} / \mathrm{ml})$. In similar experiments with gel-filtered platelets, polyclonal anti-Vn and monoclonal anti-Vn antibodies 011-292 and 011-58 inhibited thrombin-induced aggregation (Fig. 7). Control antibodies had no effect on aggregation. Several other monoclonal anti-Vn antibodies at the same concentration did not inhibit platelet aggregation, presumably because they recognized epitopes not critical to platelet function.

\section{Discussion}

$\mathrm{Vn}$ is a member of a large family of proteins that share a common RGD sequence and function in cell adhesion (9). Its role in plasma in inhibiting the complement cascade has been well documented (3). It also appears to have procoagulant activity and prevents the heparin-catalyzed inactivation of thrombin by anti-thrombin III (4-6). Although Vn binds to cells via an RGD-containing domain and is related to other multifunctional adhesive glycoproteins, its function as a cell adhesion molecule in biological systems has not been well defined. In vitro, it can mediate attachment of cells to plastic surfaces (7), but its role in the extracellular matrix or in other biological systems has been unclear.

Our data demonstrate specific and saturable binding of purified $\mathrm{Vn}$ to the activated platelet surface with a $K_{\mathrm{d}}$ of 


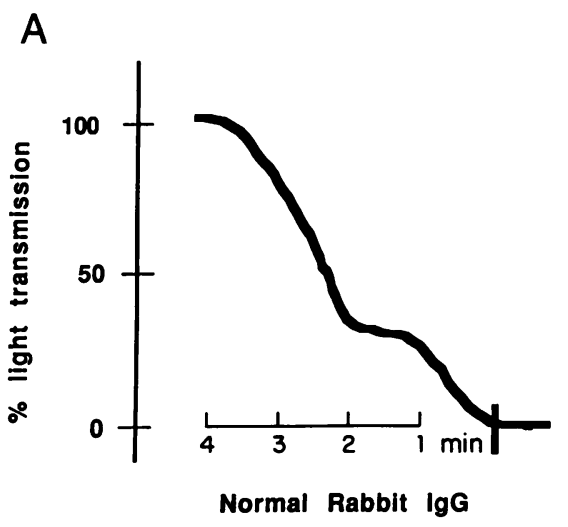

B

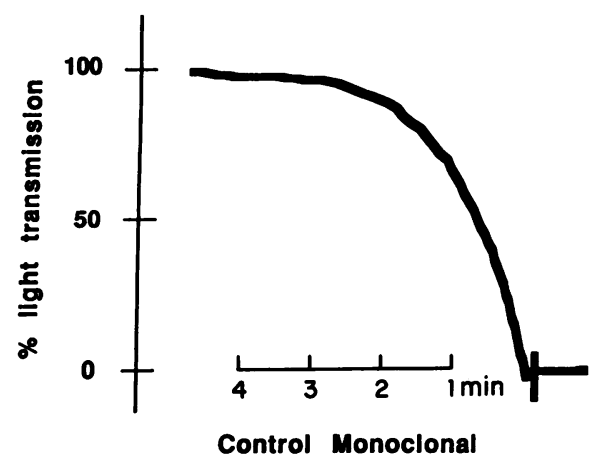

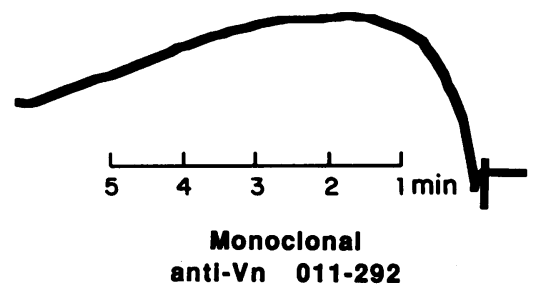

Figure 7. Inhibition of platelet aggregation by anti- $\mathrm{Vn}$ antibodies. Monospecific polyclonal anti-Vn IgG or control IgG (100 $\mu \mathrm{g} / \mathrm{ml}$ ) were added to platelet rich plasma before the addition of epinephrine $(10,5$, or $2 \mu \mathrm{M})$, ADP $(6 \mu \mathrm{M})$, thrombin $(0.5$, 0.25 , or $0.1 \mathrm{U} / \mathrm{ml})$, or collagen ( 150 $\mu \mathrm{g} / \mathrm{ml})$. In $A, 2 \mu \mathrm{M}$ epinephrine-induced aggregation in platelet rich plasma was inhibited by anti-Vn IgG but not by control IgG. In the presence of anti-Vn IgG, a primary wave but no secondary wave is seen. In $B$, thrombin induced aggregation of gelfiltered platelets was inhibited by monoclonal anti-Vn antibody 011-292 but not by an irrelevant monoclonal antibody.
93-320 nM and 8,000-23,000 sites per platelet with different agonists. These data are consistent with those reported for fibrinogen, von Willebrand factor, and fibronectin binding to platelets $(11-13,15,17,18)$. The affinities of all four ligands for the platelet surface are similar, but fibrinogen and $\mathrm{Vn}$ are found in equimolar concentrations in plasma ( $7 \mu \mathrm{M})$, and in 3and 170-fold molar excess over fibronectin and von Willebrand factor, respectively. This suggests that in vivo $\mathrm{Vn}$ may compete with fibrinogen for binding. Binding is inhibited by EDTA, as well as by the cell adhesion peptide RGDS, purified fibrinogen, and by antibodies to the platelet glycoprotein IIb/ IIIa complex, suggesting that this complex is the site for $\mathrm{Vn}$ binding to activated platelets. Endogenous $\mathrm{Vn}$ is expressed on the platelet surface after stimulation and release. Only 1,080 molecules of anti-Vn antibody bound per platelet. Steric considerations may limit the availability of epitopes, and therefore the amount of antibody bound does not accurately reflect the amount of $\mathrm{Vn}$ present within the platelet or the number of $\mathrm{Vn}$ binding sites on the platelet membrane. Aspirinated platelets stimulated with epinephrine do not release their granule contents $(31,32)$, and although they bind exogenous $\mathrm{Vn}$, they do not express endogenous stores. The discrepancy observed in the $B_{\max }$ with different agonists is most consistent with competition from released platelet Vn stores with thrombin but not epinephrine or ADP in aspirinated platelets. Vn binding to resting platelets was nonsaturable and was not inhibited by excess cold Vn, EDTA, or antibodies to GPIIb/IIIa. When analyzed by the LIGAND program, binding to resting platelets had a $K_{\mathrm{d}}$ of $10 \mu \mathrm{M}$, which is not within a physiologic range for this ligand. The inhibition of platelet aggregation that was observed with antibodies to $\mathrm{Vn}$ suggests that $\mathrm{Vn}$ may serve to stabilize the macromolecular complex responsible for platelet aggregation.

Since the initial submission of this paper, the binding of $\mathrm{Vn}$ to activated platelets has also been reported (33). In contrast to our data, only 5,000 sites/platelet were identified, and the binding measured was not reversible. Both studies support the role for GPIIb/IIIa in Vn binding to the platelet surface. Competition from released stores of endogenous platelet adhesive proteins for binding to GPIIb/IIIa may explain the observed differences in Vn binding.

GPIIb/IIIa functions as a promiscuous receptor for multiple RGD-containing proteins $(10,34)$. Purified GPIIb/IIIa incorporated into liposomes binds fibrinogen, fibronectin, von Willebrand factor, and Vn (24). Other receptors for Vn have been identified (26) that share an identical beta subunit (GPIIIa) (35). This family of receptors, termed integrins, functions in cell-cell and cell-matrix interactions $(36,37)$. This family of receptors includes the fibronectin receptor, a Vn receptor, and platelet GP IIb/IIIa. Recently, a new integrintype $\mathrm{Vn}$ receptor on platelets has been reported with an alpha chain that is identical to that of the $\mathrm{Vn}$ receptor on endothelial cells (CD51) (38). This recently described receptor is not mediating the binding observed in our studies, since 10E5 which does not recognize the $\mathrm{Vn}$ alpha chain inhibited $\mathrm{Vn}$ binding as well as 7E3 and polyclonal anti-IIb/IIIa, but LM609 did not. In addition, the copy number identified by LM609 is reportedly only $1,485 /$ platelet $(39,40)$ or may be lower (Coller, B. S., D. A. Cheresh, E. Asch, and U. Seligsohn, manuscript submitted for publication). We cannot rule out a small contribution of binding mediated by the Vn receptor, but RGD-containing ligands bind to the $\mathrm{Vn}$ receptor on endothelial cells in an 
activation-independent manner, and this is not true of the Vn binding to platelets that we have characterized. In addition, a monoclonal antibody to the endothelial cell $\mathrm{Vn}$ receptor (LM609) had no measurable effect on Vn expression on the platelet surface. We conclude that GPIIb/IIIa and not the recently reported endothelial cell $\mathrm{Vn}$ receptor is responsible for the activation-dependent platelet $\mathrm{Vn}$ binding that we have observed.

Platelet activation leads to a conformational or microenvironmental alteration of the GPIIb/IIIa complex, which results in the induction of binding sites for several ligands (34). Fibrinogen appears to be the major ligand for the GPIIb/IIIa complex, but fibronectin and von Willebrand factor also bind to this complex on the platelet surface (41). Antibodies to fibrinogen and fibronectin inhibit platelet aggregation, as do antibodies directed against the GPIIb/IIIa complex $(20,21$, 42). Recent evidence suggests that thrombospondin, another alpha granule protein, participates in a macromolecular complex on the platelet surface between fibrinogen bound to GPIIb/IIIa and a specific platelet membrane thrombospondin receptor $(43,44)$. Antibodies to thrombospondin, as well as antibodies directed at the receptor inhibit platelet aggregation, and interfere with fibrinogen binding $(20,43)$. Although $\mathrm{Vn}$ can form disulfide-linked dimers and under these conditions may form a bivalent ligand linking platelets, our autoradiography data suggest that platelet bound $\mathrm{Vn}$ is monomeric. Vn, like fibronectin, and in contrast to thrombospondin, fibrinogen, and von Willebrand factor is univalent with respect to the platelet surface. The binding site is RGD dependent and there is only one RGD per $\mathrm{Vn}$ molecule. Therefore, the role of $\mathrm{Vn}$ in supporting platelet aggregation is not likely to be that of a primary ligand like fibrinogen. The mechanism by which antibodies directed against $\mathrm{Vn}$ inhibit platelet aggregation are not clear. However, since several monoclonal antibodies to $\mathrm{Vn}$ had no effect on platelet aggregation, a specific domain of $\mathrm{Vn}$ appears to be important in this regard.

Our data suggest that in vivo Vn may play a role in platelet aggregation, perhaps by participating in the formation of a large complex on the platelet surface composed of fibrinogen, von Willebrand factor, thrombospondin, and fibronectin. Fibrinogen binding to GPIIb/IIIa is critical for normal platelet aggregation. The stabilization of the platelet aggregate appears to occur secondary to release of platelet granule contents. Anti-Vn antibody prevents the second wave of platelet aggregation in both platelet-rich plasma and gel-filtered platelets. Similar data have been published with antibodies to thrombospondin $(43,45,46)$. Secreted Vn, released upon platelet stimulation like thrombospondin, or bound to the platelet surface from plasma, may serve to stabilize the platelet aggregate.

Recently, the binding of $\mathrm{Vn}$ to other cell types has been described and a variety of cellular receptors have been identified $(35,47)$. The role of $\mathrm{Vn}$ in mediating platelet-cell or cellcell interactions remains to be defined. $\mathrm{Vn}$ in the extracellular matrix may facilitate platelet adhesion to exposed subendothelium. Endogenous platelet Vn may serve to stabilize the platelet-platelet interactions when platelets are activated and platelet granule contents are released. Recent data have demonstrated platelet activation by the cytolytic complement complex C5b-9 (48). Platelet Vn may also serve to inactivate C5b-9 that binds to innocent bystander platelets in areas of inflammation and complement activation.

\section{Acknowledgments}

We wish to thank Ms. Amy Eckert and Ms. Marika Kurer for expert technical assistance. We thank Dr. John Tamerius (Cytotech) for the generous gift of anti-Vn monoclonal antibodies. We thank Dr. Barry Coller (State University of New York, Stony Brook, NY) for his kind gift of 7E3 and 10E5 antibodies. We thank Dr. David Cheresh (Scripps Clinic) for his kind gift of LM609. We also thank Dr. Ralph Nachman and Dr. Victor Nussensweig for helpful discussions and encouragement.

Dr. Asch was the recipient of an Irvington House Institute for Medical Research Fellowship. This work was partially supported by a grant from the Lupus Foundation of America, Westchester Chapter.

\section{References}

1. Jenne, D., and K. K. Stanley. 1985. Molecular cloning of S-protein, a link between complement, coagulation and cell-substrate adhesion. EMBO (Eur. Mol. Biol. Organ.) J. 4:3153-3157.

2. Hayman, E. G., M. D. Pierschbacher, Y. Ohgren, and E. Ruoslahti. 1983. Serum spreading factor (vitronectin) is present at the cell surface and in tissues. Proc. Natl. Acad. Sci. USA. 80:4003-4007.

3. Podack, E. R., W. P. Kolb, and H. J. Muller Eberhard. 1977. The SC5b-7 complex: formation, isolation, properties, and subunit composition. J. Immunol. 119:2024-2029.

4. Podack, E. R., B. Dahlback, and J. H. Griffin. 1986. Interaction of S-protein of complement with thrombin and antithrombin III during coagulation: protection of thrombin by S-protein from antithrombin III inactivation. J. Biol. Chem. 261:7387-7392.

5. Ill, C. R., and E. Ruoslahti. 1985. Association of thrombin-antithrombin III complex with vitronectin in serum. J. Biol. Chem. 260:15610-15615.

6. Jenne, D., F. Hugo, and S. Bhakdi. 1985. Interaction of complement S-protein with thrombin-antithrombin complexes: a role for the S-protein in haemostasis. Thromb. Res. 38:401-412.

7. Barnes, D. W., and J. Silnutzer. 1983. Isolation of human serum spreading factor. J. Biol. Chem. 258:12548-12552.

8. Dahlback, K., H. Lofberg, and B. Dahlback. 1986. Localization of vitronectin (S-protein of complement) in normal human skin. Acta Derm. Venereol. (Stockh.). 66:461-467.

9. Suzuki, S., A. Oldberg, E. G. Hayman, M. D. Pierschbacher, and E. Ruoslahti. 1985. Complete amino acid sequence of human vitronectin deduced from cDNA Similarity of cell attachment sites in vitronectin and fibronectin. EMBO (Eur. Mol. Biol. Organ.) J. 4:25192524.

10. Plow, E. F., A. H. Srouji, D. Meyer, G. Marguerie, and M. H. Ginsberg. 1984. Evidence that three adhesive proteins interact with a common recognition site on activated platelets. J. Biol. Chem. 259:5388-5391.

11. Marguerie, G. A., E. F. Plow, and T. S. Edgington. 1979. Human platelets possess an inducible and saturable receptor specific for fibrinogen. J. Biol. Chem. 254:5357-5363.

12. Bennett, J., and G. Vilaire. 1979. Exposure of platelet fibrinogen receptors by ADP and epinephrine. J. Clin. Invest. 64:1393-1400.

13. Peershke, E., and M. Zucker. 1981. Fibrinogen receptor exposure and aggregation of human blood platelets produced by ADP and chilling. Blood. 57:661-670.

14. Peerschke, E. I., M. B. Zucker, R. A. Grant, J. J. Egan, and M. M. Johnson. 1980. Correlation between fibrinogen binding to human platelets and platelet aggregability. Blood. 55:841-847.

15. Fujimoto, T., S. Ohara, and J. Hawiger. 1982. Thrombin induced exposure and prostaglandin induced inhibition of receptors for FVIII/VWF on human platelets. J. Clin. Invest. 69:1212-1222.

16. Gralnick, H., S. Williams, and B. Coller. 1984. Fibrinogen competes with von Willebrand factor for binding to the glycoprotein IIb/IIIa complex when platelets are stimulated with thrombin. Blood. 64:797-800. 
17. Gardner, J., and R. Hynes. 1985. Interaction of fibronectin with its receptor on platelets. Cell. 42:439-448.

18. Plow, E., and M: Ginsberg. 1981. Specific and saturable binding of plasma fibronectin to thrombin stimulated human platelets. $J$. Biol. Chem. 256:9477-9482.

19. Ginsberg, M. H., J. D. Wencel, J. G. White, and E. F. Plow. 1983. Binding of fibronectin to alpha-granule-deficient platelets. $J$. Cell Biol. 97:571-573.

20. Coller, B. S., E. I. Peerschke, L. E. Scudder, and C. A. Sullivan. 1983. A murine monoclonal antibody that completely blocks the binding of fibrinogen to platelets produces a thrombasthenic-like state in normal platelets and binds to glycoproteins IIb and/or IIIa. J. Clin. Invest. 72:325-338.

21. Bennett, J. S., J. A. Hoxie, S. F. Leitman, G. Vilaire, and D. B. Cines. 1983. Inhibition of fibrinogen binding to stimulated human platelets by a monoclonal antibody. Proc. Natl. Acad. Sci. USA. 80:2417-2422.

22. Dixit, V. M., D. M. Haverstick, K. ORourke, S. W. Hennessy, T. J. Broekelmanp, J. A. McDonald, G. A. Grant, S. A. Santoro, and W. A. Frazier. 1985. Inhibition of platelet aggregation by a monoclonal antibody against human fibronectin. Proc. Natl. Acad. Sci. USA. 82:3844-3848.

23. Tollefsen, D. M., and P. W. Majerus. 1975. Inhibition of human platelet aggregation by monovalent antifibrinogen antibody fragments. J. Clin. Invest. 55:1259-1268.

24. Pytela, R., M. D. Pierschbacher, M. H. Ginsberg, E. F. Plow, and E. Ruoslahti. 1986. Platelet membrane glycoprotein IIb/IIIa: member of a family of Arg-Gly-Asp-specific adhesion receptors. Science (Wash. DC). 231:1559-1562.

25. Dahlback, B., and E. R. Podack. 1985. Characterization of human $S$ protein, an inhibitor of the membrane attack complex of complement: demonstration of a free reactive thiol group. Biochemistry. 24:2368-2374.

26. Cheresh, D. A. 1987. Human endothelial cells synthesize and express an Arg-Gly-Asp-directed adhesion receptor involved in attachment to fibrinogen and von Willebrand factor. Proc. Natl. Acad. Sci. USA. 84:6471-6475.

27. Fraker, P. J., and J. C. Speck. 1980. Protein and cell membrane iodinations with a sparingly soluble chloramide 1,3,4-6 tetrachloro $3 a$, 6a-diphenyl glycoluril. Biochem. Biophys. Res. Commun. 80:849-857.

28. Tangen, O., J. H. Berman, and P. Marfey. 1971. Gel filtration: a new technique for separation of platelets from plasma. Thromb. Diath. Haemorrh. 25:269-278.

29. Burnette, W. N. 1981. Western blotting: electrophoretic transfer of proteins from SDS-PAGE to unmodified nitrocellulose and radiographic detection with antibody and radioiodinated protein. Anal. Biochem. 112:195-203.

30. Feinman, R. D., J. Lubowsky, I. Charo, and M. P. Zabinski. 1977. The lumi-aggregometer: a new instrument for simultaneous measurement of secretion and aggregation by platelets. J. Lab. Clin. Med. 90:125-129.

31. Silver, M., J. Smith, C. Ingerman, and J. Kossis. 1973. Arachidonic acid-induced platelet aggregation and prostaglandin formation. Prostaglandins. 4:863.
32. Rao, G. H., G. Johnson, and J. White. 1980. Influence of epinephrine on the aggregation response of aspirin treated platelets. Prostaglandins Med. 5:45-58.

33. Thiagarajan, P., and K. Kelly. 1988. Exposure of binding sites for vitronectin following stimulation. J. Biol. Chem. 263:3035-3038.

34. Plow, E. F., R. P. McEver, B. S. Coller, V. L. Woods, Jr., G. A. Marguerie, and M. H. Ginsberg. 1985. Related binding mechanisms for fibrinogen, fibronectin, von Willebrand factor, and thrombospondin on thrombin-stimulated human platelets. Blood. 66:724-727.

35. Ginsberg, M. H., J. Loftus, J. J. Ryckwaert, M. Pierschbacher, R. Pytela, E. Ruoslahti, and E. F. Plow. 1987. Immunochemical and amino-terminal sequence comparison of two cytoadhesins indicates they contain similar or identical beta subunits and distinct alpha subunits. J. Biol. Chem. 262:5437-5440.

36. Hynes, R. O. 1987. Integrins: a family of cell surface receptors. Cell. 48:549-554.

37. Phillips, D. R., I. F. Charo, L. V. Parise, and L. A. Fitzgerald. 1988. The platelet membrane glycoprotein IIb-IIIa complex. Blood. 71:831-843.

38. Lam, S. C., E. F. Plow, S. E. DSouza, D. A. Cheresh, A. L. Frelinger III, and M. H. Ginsberg. 1989. Isolation and characterization of a platelet membrane protein related to the vitronectin receptor. $J$. Biol. Chem. 264:3742-3749.

39. Lawler, J., R. Weinstein, and R. O. Hynes. 1988. Cell attachment to thrombospondin. The role of ARG-GLY-ASP, calcium, and integrin receptors. J. Cell Biol. 107:2351-2356.

40. Lawler, J., and R. O. Hynes. 1989. An integrin receptor on normal and thrombasthenic platelets that binds thrombospondin. Blood. 74:2022-2027.

41. George, J. N., A. T. Nurden, and D. R. Phillips. 1984. Platelet aggregation. N. Engl. J. Med. 311:1084-1091.

42. Dixit, V. M., D. M. Haverstick, K. O'Rourke, S. W. Hennessy, T. J. Broekelmann, J. A. McDonald, G. A. Grant, S. A. Santoro, and W. A. Frazier. 1985. Inhibition of platelet aggregation by a monoclonal antibody against human fibronectin. Proc. Natl. Acad. Sci. USA. 82:3844-3848.

43. Leung, L. L. 1984. Role of thrombospondin in platelet aggregation. J. Clin. Invest. 74:1764-1772.

44. Asch, A. S., J. Barnwell, R. L. Silverstein, and R. L. Nachman. 1987. Isolation of the thrombospondin membrane receptor. J. Clin. Invest. 79:1054-1061.

45. Dixit, V. M., D. M. Haverstick, K. M. O'Rourke, S. W. Hennessy, G. A. Grant, S. A. Santoro, and W. A. Frazier. 1985. A monoclonal antibody against human thrombospondin inhibits platelet aggregation. Proc. Natl. Acad. Sci. USA. 82:3472-3476.

46. Gartner, T. K., D. A. Walz, M. Aiken, L. S. Spires, and M. L. Ogilvie. 1984. Antibodies against a $23 \mathrm{Kd}$ heparin binding fragment of thrombospondin inhibit platelet aggregation. Biochem. Biophys. Res. Commun. 124:290-295.

47. Baetscher, M., D. W. Pumplin, and R. J. Bloch. 1986. Vitronectin at sites of cell-substrate contact in cultures of rat myotubes. $J$. Cell Biol. 103:369-378.

48. Wiedmer, T., and P. J. Sims. 1985. Effect of complement proteins C $5 \mathrm{~b}-9$ on blood platelets: evidence for reversible depolarization of membrane potential. J. Biol. Chem. 260:8014-8019. 